\title{
Ekmeklik ( $T$. aestivum) ve Makarnalık ( $T$. durum) Buğday Genotiplerinin Bor Alımı Üzerine Fosforun Etkisi
}

\author{
Aydin GÜNEŞ' \\ Geliş Tarihi: $16,05.2000$
}

\begin{abstract}
Ozet: Ekmeklik ve makarnalık bugday genotiplerinin bor (B) alımı Ozerine fosorun (P) etkisinin araștırıldıgı denemede, 27 adet buğday (17 ekmekllk ve 10 makarnalik) genotipiyle sera denemesi kuruimuştur. Fosfor toprağa 20 ve $80 \mathrm{mg} \mathrm{kg}$ düzeylerinde uygulanmıștır. Tüm buğday genotiplerinin B konsantrasyonları $P$ uygulaması ile duşǘştur. Ekmeklik buğday genotiplerinin $B$ konsantrasyonunda, $\mathrm{P}$ uygulamasına bağll olarak \%24 l0k, makarnalık genotiplerde ise $\% 11^{\prime}$ lik bir azaima belirlenmiştir. Bu denemede ekmeklik buğday genotiplerinin P/B oranları, makarnalikiara göre doşok bulunmuștur. Düşăk ve yóksek $P$ düzeylerinde makarnalik buğday genotiplerinin B içerikleri, ekmeklik genotiplere göre daha yäksek belirlenmiștir.
\end{abstract}

Anahtar Kellimeler: Buğday genotipleri, P uygulaması, B alımı, B konsantrasyonu

\section{Boron Uptake in Bread ( $T$. aest/vum) and Durum ( $T$. durum) Wheat Genotypes in Relation to Phosphorus Nutrition}

\begin{abstract}
The effect of phosphorus (P) on the uptake of boron $(B)$ was examined in 27 wheat (17 bread and 10 durum) genotypes in greenhouse experiment. Phosphorus was applied at 20 and $80 \mathrm{mg} \mathrm{kg-1}$ levels. The B content of all genotypes was decreased by application of $P$. Boron contents of bread wheat genotypes was decreased by application of $P$ at level of $24 \%$. However, boron contents of durum wheat genotypes was decreased by application of $P$ at level of $11 \%$. This experiment shows that ratio of $\mathrm{P} / \mathrm{B}$ of bread wheat genotypes was lower than that of durum wheat genotypes. Boron contents of durum wheat genotypes was found to be higher than bread wheat genotypes at the low and high level phosphorus.
\end{abstract}

Key Words: Wheat genotypes, P supply, B uptake, B content

\section{Giris}

Tarkiye' de tarımsal Öretim içerisinde tahılların onemi çok bayoktür. Olkemizde ișlenen tarim arazilerinin yaklaşık \%80' inde tahıl üretimi yapilmakta, tahil üretiminin yapildiğı alanların yaklaşık \%65' inde de buğday üretimi gerçekleşmektedir (Anonim, 1997).

Bitkisel uretimi sınırlayan temel beslenme sorunlarının başında, topraklardaki besin maddelerinin bitkilere yarayışlıı̆ı̆ın daşukklağa gosterilebilir. Kurak ve yarıkurak bolge topraklarında bitkilerde B noksanlığ ya da toksikliği sıkça karşılaşılan ónemli beslenme sorunlarindandır (Gupta ve ark. 1985). Kurak Iklim bölgelerinin tipik özelliklere sahip olan Orta Anadolu Bölgesi' nde tahil ekimi yapilan topraklann bitkiye yarayışlı B kapsamları 0,01 ppm ile 11,0 ppm arasında değişmekte olup, ortalama $0,62 \mathrm{ppm}$ ' dir. Bu sonuçlar sınır değerleri ile karşılaştırıldığında toprakların \%62' sinin noksanlik sinirinda $(<0,5 \mathrm{ppm} B), \% 2,52^{\prime}$ sinin toksiklik sinirinda $(>2,5$ ppm B) olduğu belirlenmiştir (Eyüboğlu ve ark. 1999). Bor bitkilerde oksin ve fenol metabolizmasında, mernbran permeabilitesinde, polen çimlenmesinde ve polen tapa bayamesinde, meyve miktar ve kalitesinde önemli roller ustlenmektedir (Marschner, 1995; Holevas ve Bris, 1980). Borun topraktan alınarak bitkide taşınımının transpirasyon miktar ve hızıyla ilișkili olduğu bilinmekte ve bu nedenle kurak iklimlerde $B$ yeterince alınamamakta ve bunun sonucu olarak noksanlık görolmekte veya alinan $B$ bitkinin belirli yerlerinde birikerek toksik etki yapabilmektedir (Marschner, 1995). Kalsiyumun B' un toksik etkisini gidermede etkili olduğu birçok araştırıcı tarafindan ortaya konulmuştur (Gupta, 1972; Gupta ve Mcleod, 1981, Oyewole ve Aduayi, 1992), Ote taraftan, B alınımı ve bitkideki taşınımı $P$ alımı ile yakından iliş̧ilidir, gerçekten de $\mathrm{P}$ ve $\mathrm{B}^{\prime}$ un biyokimyasal ve fizyolojik davranışlari birbirine benzerlikler góstermektedir (Bergmann, 1992). Kireçli ve yüksek $\mathrm{pH}^{\prime}$ II topraklarda B bitkiler tarafindan borat formunda fosfat anyonuna benzer sekilde alınirlar (Bergmann, 1992). Fosfor B üzerine etkileşimde bulunarak bitki tarafından $B^{\prime}$ un alımını olumsuz yönde etkileyebilmektedir (Pollard ve ark. 1977). Gerçekten de yapılan çalışmalarda aşırı $P$ uyguiamasinın bitkilerin B alımını doşurebileceği ortaya konulmuştur (Bingham ve Garber, 1960; Bingham ve ark. 1958). Topraktaki borun yarayışılığı azerine $\mathrm{pH}$ önemli bir faktördur. Yüksek toprak $\mathrm{pH}^{\prime}$ lannda bitkilere yarayışı $\mathrm{B}$ azalmaktadır. Toprakların çuzünebilir B kapsamları ile toprak $\mathrm{pH}^{\prime}$ si arasında önemli ilişkiler belirlenmiştir (Berger ve Truog, 1945; Elrashidi ve O' Connor, 1982). Turkiye topraklarının kirec, $\mathrm{pH}$ ve organik madde yönünden sahip oldugu ózellikler, topraklarımızda fosfor yarayıșlilığını ciddi şekilde sinilayabllecek durumdadır. Torkiye'nin de içinde bulunduğu Akdeniz ve Bati Asya alkelerinde topraklarda bitkisel aretimi sınırlayan temel beslenme sorunlarının bassında, topraklardaki P'un bitkilere yarayıșiliğınin duşuklügü gösterilmektedir (Cooper ve ark. 1987; Matar ve ark. 1992). Ülkemiz topraklarinin \%82' sinde $\mathrm{pH}, 7$ ve uzerinde, $\% 65^{\prime}$ inde organik madde az ve cok az duzeyinde, bitkilerce alınabilir P miktarı ise topraklarımızın

\footnotetext{
Ankara Univ, Ziraat Fak. Toprak BölümÜ-Ankara
} 
$\% 58^{\prime}$ inde yetersiz dazeyde $\left(6 \mathrm{~kg} \mathrm{P}_{2} \mathrm{O}_{5} / \mathrm{da}\right)$ bulunmuștur, yine ulkemiz toprakları kireç kapsamları yönünden incelendiğinde yaklaşık \%77' si kireçi topraklar sinifina girmektedir (Eyáboğlu, 1999). Bu sonuçlar, Turkiye'de toprakların boyok bir bölomande $P$ gabrelemesinin kaçinilmaz olduğunu göstermektedir. Yaklaşık son 30 yil içerisinde P'lu gübre taketimimizin \%1500' lak bir artış göstererek 600000 tona yaklaștığı bildirilmektedir (Kacar ve Samet, 1996). Ancak burada azerinde durulması gereken onemli bir nokta, aşın fosforlu gübreleme sonucu topraklarda fosfor birikiminin olabileceği bununda mikro elementlerin yanında ozellikle kurak koşullarda PXB interaksiyonu sonucu bitkilerin $B$ ile beslenmeleri bakımından ciddi sorunların ortaya çıkabileceğidir.

Bu çalışmada, Orta Anadolu Bölgesinde yaygın olarak üretimi yapilan 27 adet buğday genotipinin yeterli ve yaksek dazeylerde uygulanan fosfora bağlı olarak, toprakta bulunan $\mathrm{B}^{\prime}$ dan yararlanmaları bakımından genotipsel farkliliklannı ortaya koymak ve elde olunacak sonuçlardan hareketle B' u etkin külanan genotipleri seçerek ileriye yönelik daha kapsamlı çalışmalar için veri tabanlarını oluşturmak amaçlanmıştır.

\section{Materyal ve Yöntem}

Araştirma sera koşullarında iki farklı fosfor dozeyinde $\left(P_{20}\right.$ ve $\left.P_{80}\right) 1600 \mathrm{~g}$ toprak alan saksılarda 27 adet buğday (17 adet ekmeklik ve 10 adet makarnalik) genotipi yetiştirilerek yürüülmuștúr. Her saksıya başlangıçta $20^{\prime}$ şer adet buğdaỹ tohumu ekilmiş ve daha sonra saksilarda 12 adet bitki kalacak şekilde seyreltilmiştir. Denemede teksturo siltli killi tın, $\mathrm{pH}^{\prime}$ si 8,14, kireç kapsami \%7,54, EC' si $0,21 \mathrm{dS} \mathrm{m}^{-1}$, organik maddesi $\% 0,80$, bitkiye yaray!sil $\mathrm{K}$, $P$ ve $B$ kapsamlari sırasılyla $697 ; 5,13$ ve $2,60 \mathrm{mg} \mathrm{kg}^{-1}$ olan toprak kullanilmiştir.

Denemede saksilara plana göre 20 ve $80 \mathrm{mg} \mathrm{kg}^{-1} \mathrm{P}$ $\left(\mathrm{KH}_{2} \mathrm{PO}_{4}\right)$ uygulanmiştir. Temel gübreleme olarak bütún saksılara başlangıçta $200 \mathrm{mg} \mathrm{kg}^{-1} \mathrm{~N}$ ve gelişmenin 20 . gününe $100 \mathrm{mg} \mathrm{kg}^{-1} \mathrm{~N}$ olmak azere toplam $300 \mathrm{mg} \mathrm{kg}^{-1}$ $N$, fosfor uygulamasından gelen $K^{\prime}$ u dengelemek için $\mathrm{K}_{2} \mathrm{SO}_{4}$ ek gäbrelemesi yapilmıştır. Bitkiler 49 ganläk bir gelişme süresinden sonra toprak yüzeyinden kesilmek suretiyle hasat edilmiștir. Saf su ile yıkanan ömekler $65^{\circ} \mathrm{C}^{\prime}$ de sabit ağırlığa gelinceye kadar kurutulmuş ve kuru ağırlıkları belirlenmiştir. Kuru yakma yöntemine göre yakılan bitki orneklerinde toplam $\mathrm{P}$ spektrofotometrik olarak (Kitson ve Mellon, 1944), topiam B azomethin-H yơntemine gơre yine spektrofotometrik olarak belirlenmiştir (Wolf, 1974).

Tesaduf parselleri deneme tertibine göre 4 tekrarlamalı olarak planlanan denemeden elde edilen veriler MINITAB paket proğramında istatistiki olarak değerlendirilmiş, ayrıca ele alınan değişkenler arasındaki korelasyon ilişkileri belirlenmiştir.

\section{Bulgular ve Tartışma}

Buğday genotiplerinin kuru ağırlıklan ve $P$ etkinlikleri: Fosfor uygulamalanna bağli olarak buğday genotiplerinin kuru ağırlıklan ile P-etkinlikleri Çizelge $1^{\prime}$ de toplu olarak verilmiştir. Cizelge ${ }^{\prime}$ in incelenmesinden buğday bitkilerinin kuru ağırlıkarında $P$ uygulamasına bağlı olarak onnemli farkłılikların olduğu görülmektedir $(p<0,01)$. Doşak $P$ dozeyinde buğday genotiplerinin oluşturdukları kuru madde miktarlan ortalama olarak ekmeklik çeşitlerde 4,68 g makarnalık çeşitterde ise $4,23 \mathrm{~g}$ olmuştur. Yeterli dozeyde P uygulamasinda ise ekmeklik ve makarnalık çeşitlerde kuru madde miktarı sırasıyla 5,49 $g$ ve $4,39 \mathrm{~g}$ olarak belirlenmiștir. Buğday genotiplerinin $P$ etkinlikleri ise genotiplere bağlı olarak farklılıklar gostermekle beraber ekmeklik ceşitlerin P' u daha etkin kullandiklan görulmektedir (ortalama $\% 85,11$ ). Makarnalık çeșitlerde ise bu oran ortalama $\% 87,50^{\prime}$ ye ulaşmaktadir. Fosfor eksikligi kosullarında bitkilerin rizosfer pH'sını dōşürmesi ve rizosfere organik asitler salgılaması, $P$ eksikliği koşullarinda adaptasyonda buyuak bir önem taşımaktadır. Kók bölgesinde $\mathrm{pH}^{\prime}$ nın doşmesi fosforun yarayışlılığını önemli ölçode artırmaktadir. Fosfor noksanliğı koşullarında beyaz bakla, kolza, yonca ve turp gibi bir çok bitki türünde rizosfer $\mathrm{pH}^{\prime}$ ' sında duşmenin

Çizelge 1، Buğday genotiplerinin kuru ağırlikları ve $P$ etkinlikleri

\begin{tabular}{|c|c|c|c|}
\hline \multirow[t]{2}{*}{ Genotipler } & \multicolumn{2}{|c|}{ Kuru Ağ. (g) } & \multirow{2}{*}{$\begin{array}{c}\text { Petkinliģi, \% } \\
\text { P20/PBo }\end{array}$} \\
\hline & P20 & P80 & \\
\hline Sivas $111 / 33$ & 5.57 & 6.07 & 92 \\
\hline Sultan & 5.15 & 5.81 & 87 \\
\hline Tarkmen & 5.01 & 5.52 & 91 \\
\hline |kizce 96 & 4.90 & 5.67 & 86 \\
\hline Kırkpinar 79 & 4,91 & 5.50 & 89 \\
\hline Atay 85 & 4.32 & 5.44 & 79 \\
\hline Kirgiz & 4.58 & 5.91 & 77 \\
\hline Kıraç 66 & 4.42 & 5.20 & 85 \\
\hline Bolal 2973 & 4.89 & 5.77 & 85 \\
\hline Köse 220/39 & 5.85 & 7.30 & 80 \\
\hline Ankara 093-44 & 3.45 & 4.50 & 77 \\
\hline Mizrak 98 & 4.05 & 4.75 & 85 \\
\hline Uzunyayla & 4.17 & 5.39 & 77 \\
\hline Dağdaş & 4.33 & 4,96 & 87 \\
\hline Bezostaya & 4.53 & 5,10 & 89 \\
\hline Gerek 79 & 4.47 & 5.10 & 80 \\
\hline Gün 91 & 4.91 & 5.29 & 93 \\
\hline Ankara $98^{*}$ & 4.36 & 4.10 & 106 \\
\hline Yilmaz 98 & 4.36 & 4.47 & 98 \\
\hline Aitun 40-98 & 4.23 & 4.33 & 98 \\
\hline Gökgöl 79 & 4.26 & 4.59 & 93 \\
\hline G-1262 & 3.86 & 4.06 & 95 \\
\hline Tunca 79 & 4.84 & 4.93 & 98 \\
\hline Cakmak 79 & 4.14 & 4.50 & 82 \\
\hline Kiziltan 91 & 4.20 & 4.14 & 101 \\
\hline Akbaşak & 4.30 & 4.31 & 100 \\
\hline Kunduru 1149 & 4.16 & 4.49 & 92 \\
\hline
\end{tabular}

-Makamalik genotipler 
olduğu ve prtama organik asitlerin fazla miktarlarda salgilandiğ belirlenmiştir (Gardner ve ark. 1983; Dinkelaker ve ark. 1989; Moorby ve ark. 1985; Hoffland ve ark. 1992). Literatorlerde siniriı $P$ varligina yada gubrelemesine karşin diğer genotiplere gore daha yưksek oranlarda biyokatle veya verim oluşturabilen genotipler $P$ etkin ( $P$ eksikliğine dayanıklı) genotipler olarak tanimianmaktadir (Gabelman ve Gerloff, 1983; Graham, 1984)

Buğday genotiplerinin P konsantrasyoniarı ve P alımları: Fosfor uygulamalarina bağlı olarak gerek ekmeklik gerakse makarnalık buğday çeșitlerinin P konsantrasyoniarı onemli oranda artmıștir $(p<0,01)$ (Çizelge 2). Genotiplerin P uygulamasina gőstermiş oldukları tepkiler farkh olmuştur. Ekmeklik bug̣day genotiplerinin $P$ konsantrasyonlan dusok $P$ uygulamasında ortalama $1415 \mathrm{mg} \mathrm{kg}^{-1}$, makarnalik çeșitlerin $P$ konsantrasyonlari $1467 \mathrm{mg} \mathrm{kg}^{-1}$ olarak bulunmuştur. Yaksek $P$ duzeyinde ise, ekmeklik ve makarnalık genotipierin $P$ konsantrasyonları sırasıyla ortalama $2792 \mathrm{mg} \mathrm{kg}^{-1}$ ve $3260 \mathrm{mg} \mathrm{kg}^{-1}$ olarak saptanmıștır (Çizelge 2) Bitkilerin $P$ alımları hesaplandığında ekmeklik buğday genotiplerinin gerek doşok gerekse yoksek $P$ uygulamalarında makamalik genotiplere göre daha fazla $P$ aldıkları saptanmıștır. Gerçektende dassok fosfor duzeyinde ekmeklik çeşitlerin ortalama $P$ alımlari $6,60 \mathrm{mg}$ saksi ${ }^{-1}$ olarak bulunurken, bu değer makarnalık genotiplerde ortalama $6,27 \mathrm{mg}^{\text {saksi }}{ }^{-1}$ olarak belirienmiştir (Cizelge 3). Yaksek P uygulamasinda da benzer durum gorolmektedir.

Cizelge 2. Bugdday genotiplerinin P konsantrasyonları ve alimiarı

\begin{tabular}{|c|c|c|c|c|}
\hline \multirow[t]{2}{*}{ Genotipler } & \multicolumn{2}{|c|}{ P kons. ppm } & \multicolumn{2}{|c|}{$\begin{array}{c}\text { P alimu, } \\
\text { mg saksit }\end{array}$} \\
\hline & P20 & P80 & P20 & P80 \\
\hline Sivas $111 / 33$ & 1410 & 2674 & 7.88 & 16.23 \\
\hline Sultan & 1410 & 2464 & 7.27 & 14.37 \\
\hline Torkmen & 1278 & 2806 & 6.41 & 15.47 \\
\hline |kizce 96 & 1254 & 2584 & 6.16 & 14.67 \\
\hline Kirkpinar 79 & 1296 & 2794 & 6.37 & 15.31 \\
\hline Atay 85 & 1284 & 2818 & 5.56 & 15.28 \\
\hline Kirgiz & 1428 & 3093 & 6.54 & 18.24 \\
\hline Kiraç 66 & 1643 & 2931 & 730 & 15.30 \\
\hline Bolal 2973 & 1320 & 2320 & 6.48 & 13.42 \\
\hline Köse 220/39 & 1374 & 2374 & 8.02 & 17.34 \\
\hline Anikara 093-44 & 1554 & 3465 & 5.37 & 15.49 \\
\hline Mizrak 98 & 1494 & 2806 & 606 & 13.44 \\
\hline Uzunyayla & 1287 & 2499 & 538 & 13.47 \\
\hline Dağdaş & 1639 & 3147 & 7.10 & 15.62 \\
\hline Bezostaya & 1457 & 3189 & 6.59 & 16.26 \\
\hline Gerek 79 & 1596 & 2935 & 7.13 & 14.96 \\
\hline Gan 91 & 1336 & 2559 & 5.56 & 13.45 \\
\hline Ankara 98 & 1281 & 2692 & 5.59 & 11.21 \\
\hline Yilmaz 9B & 1476 & 2865 & 6.46 & 13.26 \\
\hline Altin 40.98 & 1409 & 3110 & 5.86 & 13.40 \\
\hline Gökgöl 79 & 1548 & 2886 & 6.56 & 13.21 \\
\hline G. -1252 & 1360 & 3474 & 5.27 & 14.01 \\
\hline Tunca 79 & 1487 & 3129 & 7,19 & 16.41 \\
\hline Çakmak 79 & 1681 & 3462 & 6.98 & 15.66 \\
\hline Krziltan 91 & 1481 & 3389 & 8.24 & 14.03 \\
\hline Akbaşak & 1457 & 3710 & 8.26 & 16,99 \\
\hline Kunduru 1149 & 1491 & 3780 & 6.20 & 16.84 \\
\hline
\end{tabular}

Buĝday genotiplerinin B konsantrasyoniari, B alımian ve P/B oranlar: Buğday genotiplerinin fosfor uygulamalanna bagli olarak $B$ konsantrasyonlannda onemli dozeylerde azalmalar belirlenmiștir $\langle p<0,01\}$ (Çizelge 3). Araştırmada duşuk duzeyde uygulanan fosfor koşullarinda deneme bitkilerinin B konsantrasyonlari geneotiplere göre buyok farkliliklar gustermiştir. Ornegin $\mathrm{P}_{20}$ düzeyinde en yoksek $\mathrm{B}, 68,9 \mathrm{mg} \mathrm{kg}^{-1}$ olarak makarnalık bir çeşit olan Ylimaz 98' do belirlenirken, en duşük B 22,2 $\mathrm{mg} \mathrm{kg}^{-1}$ ile ekmeklik çeşitlerden Sivas $111 / 33$ çeşidinde belirlenmiştir (Çizeige 3). Yokssek duzeyde $P$ uygulamasinda ortamdaki $P$ konsantrasyonunun artmasina bağlı olarak bitkilerin $B$ içerikleri geneide ciddi oranlarda azaimıştır. Gerçektende ekmeklik genotiplerden Dağdaş, makarnalik genotiplerden Ankara 98 ve Gokgöl 79 dişinda tüm genotiplerin $B$ içerikleri uygulanan $P^{\prime}$ a bağli olarak onemli dozeylerde

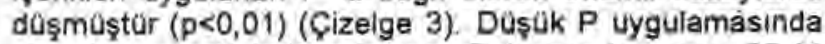
ekmeklik genotiplerin ortalama B konsantrasyonu 36,44 $\mathrm{mg} \mathrm{kg}^{-1}$ iken yoksek. $P$ uygutamasinda bu deger \%24' lak bir azalma ile ortalama $27,65 \mathrm{mg} \mathrm{kg}^{-1}$ olarak gerçekleşmiştir. Aynı şekilde makamalık genotiplerde de doşuk $P$ duzeyinde ortalama bitkilerin $B$ konsantrasyonu $50,52 \mathrm{mg} \mathrm{kg}^{-1}$ iken yöksek $P$ düzeyinde bu değer \% $1 \mathrm{f}^{\prime}$ lik bir azalma lie $44,90 \mathrm{mg} \mathrm{kg}^{-1}$ olarak bulunmuştur. Buradan goruleceği gibi ekmeklik genotiplerîn $P^{\prime}$ u daha etken kullandikları düşünölarse (Çizeige 1) bunun sonucunda bitkilerin bor konsantrasyonlarinda meydana gelen onemli azalmalarin BXP interaksiyonu ile açıklamak olasıdır. Başka bir deyişle, $P^{\prime} \mathrm{u}$ daha etken kullanan genotiplerin $B$ konsantrasyonları diğer genotiplere oranla daha fazla azalmaktadir Yüksek $P$ uygulamalanında bitkilerin $B$ alimlarınin olumsuz yönde etkilendiklerine ilișkin sonuçlan Pollard et al. (10) ve Güneş vé Alpaslan (27) yaptıkları çalişmalarla ortaya koymuşlardir. Buğday genotiplerinin B alımları da yine $P$ uygulamalarına bağlı olarak ónemil dúzeylerde azalmiştir $(P<0,01)$ (Çizelge 3). Buğday genotiplerinden Dağdaș. Ankara 98, Gökgobl 79, Ankara 093-44, Clakmak 79 ve Kunduru 1149 çeşitleri diğerlerine göre P düzeylerindeki artiştan en az etkilendikleri hatta ilk Uf genotipin B konsantrasyonlarında bir artișin söz konusu olduğu görölmektedir (Çizelge 3). Buna karşllik, Kirgiz, Mrzrak 98, Sultan ve Yilmaz 98 çeşitlerinde ise bitkilerin B konsantrasyonlari artan $\mathrm{P}$ uygulamasında boyak dușușler gostermistir (sirasiyla \%49,40; \%38,30; \%35,46 ve $\% 30,91$ ? Bu durum genotipler arasinda B alımı ile ilişkili olarak ciddi dozeylerde farklılıkların olduğunu gostermektedir. Bitki bünyesindeki besin maddelerinin oranlari, bunların fizyolojik etkinlikleri Gzerine son derece onemli etkilerde bulunmahtadir. Orneğin bitkide Fe/P, $\mathrm{P} / \mathrm{Zn}, \mathrm{K} / \mathrm{Mg}, \mathrm{P} / \mathrm{B}, \mathrm{Fe} / \mathrm{Mn}$ gibi daha bir çok besin maddesi oranlari, bunların antagonistik etkileşimlerinden dolayı anilan besinlerin bitkideki miktarları yeterli gözükse bile bitkideki işlevlenini tam olarak yerine getirememektedirler (Bergmann, 1992). Besin madideleri arasındaki oranin artması veya azaiması bir elementin fazlalığını yada noksanlığını ifade etmektedir.

Bergmann (1992) a gore, makro besin maddelerinin mikro besin maddelerine oranlannin $57 / 1$ ile $240 / 1$ arasında olduğunda optimum, 1200/1 oiduğunda mikra besin maddesi noksanlığı ve $7 / 1$ olduğunda ise mikro besin maddesi toksikliği görämektedir. 
Órneğin misır bitkisi ile yapilan çalışmalarda bazı besin maddeleri arasındaki optimum oranlar $\mathrm{P} / \mathrm{Zn}$ için yaklaşik 65; $\mathrm{P} / \mathrm{Fe}$ için yaklaşık 12 ve $\mathrm{Fe} / \mathrm{Zn}$ için yaklaşık 5 olarak tesbit edilmiştir.

Bu araştımanin konusu olan P/B oranı ile ilgili bilimsel kaynaklarda bir değere rastlanmamakla birlikte, çalışmada kullanılan buğday genotiplerinin P/B oranları boyăk farkliliklar góstermiștir. Bu bulgular ileriye yönelik çalışmalara veri tabanı oluşturması açısından onemil bir başlangıçtır. Gerçektende duşuk P duzeyinde buŏgay genotiplerinin $P / B$ oraniari incelenecek olursa sn yoksek oran Sivas 111/33 genotipinde 64 olarak, en duşôk oran ise Yilmaz 98 genotipinde 21 olarak saptanmiştır (Çizelge 3). Ekmeklik buğday genotiplerinin ortalama P/B orani 41, buna karșlık makarnalık genotiplerin $P / B$ oranı ise ortalama 30 olarak bulunmuștur. Bu durumda bitkilerin genotip ozelliklerinden ileri gelen oriemil bir 8 beslenmesi farklıikları söz konusudur.

Çizeige 3. Buğday genotiplerini B konsantrasyonian ve alımiarı lie P/B oranlan

\begin{tabular}{|c|c|c|c|c|c|c|c|}
\hline \multirow[t]{2}{*}{ Genotipler } & \multicolumn{2}{|c|}{$\begin{array}{c}\text { B kons. } \\
\text { ppm }\end{array}$} & \multicolumn{2}{|c|}{\begin{tabular}{c|} 
B alimi, \\
mg saksi
\end{tabular}} & \multicolumn{2}{|c|}{ P/B orant } & \multirow{2}{*}{$\begin{array}{c}\text { B kons. } \\
\% \\
\text { değişim }\end{array}$} \\
\hline & P20 & P80 & $\mathbf{P 2 0}$ & P80 & P20 & P80 & \\
\hline Sivas $111 / 33$ & 22.2 & 16.3 & 0.12 & 0.10 & 64 & 164 & 28.58 \\
\hline Sultan & 32.9 & 21.2 & 0.17 & 0.12 & 43 & 116 & 35.46 \\
\hline Törkmen & 35.2 & 26.4 & 0.18 & 0.15 & 36 & 106 & 25.00 \\
\hline |kizce 96 & 26.6 & 18.9 & 0.13 & 0.11 & 47 & 137 & 28.87 \\
\hline Kirkpin. 79 & 32.0 & 23.2 & 0.16 & 0.13 & 40 & 120 & 27.50 \\
\hline Atay 85 & 36.9 & 26.2 & 0.16 & 0.14 & 35 & 108 & 29.00 \\
\hline Kurgiz & 41.5 & 21.0 & 0.19 & 0.12 & 34 & 147 & 49.40 \\
\hline Kiraç 66 & 36.6 & 27.8 & 0.17 & 0.14 & 45 & 105 & 24.04 \\
\hline Bolal 2973 & 36.4 & 26.7 & 0.18 & 0.15 & 36 & 87 & 26,73 \\
\hline Köse 220/39 & 27.6 & 20.8 & 0.16 & 0.15 & 50 & 114 & 24.74 \\
\hline Ank.093-44 & 25.8 & 25.2 & 0,09 & 0.11 & 60 & 137 & 2.33 \\
\hline Mizrak 98 & 53.0 & 32.7 & 0.21 & 0.16 & 28 & 86 & 38.30 \\
\hline Uzunyayla & 45.7 & 32.8 & 0.19 & 0.18 & 28 & 76 & 28.18 \\
\hline Dağdaş & 38.1 & 40.8 & 0.17 & 0.20 & 43 & 77 & -7.09 \\
\hline Bezostaya & 45.9 & 39.3 & 0.21 & 0.20 & 32 & 81 & 14.38 \\
\hline Gerek 79 & 49.6 & 43.7 & 0.22 & 0.22 & 32 & 67 & 12.00 \\
\hline Gün 91 & 33.5 & 27.0 & 0.17 & 0.14 & 40 & 95 & 19.55 \\
\hline Ankara 98 & 50.8 & 51.8 & 0.23 & 0.21 & 26 & 52 & -1.97 \\
\hline Vulmaz 98 & 58.9 & 47.6 & 0.30 & 0.21 & 21 & 62 & 30.91 \\
\hline Altin $40-98$ & 52.0 & 45,2 & 0.22 & 0.20 & 27 & 69 & 13.17 \\
\hline Gókgớl 79 & 39.8 & 41.0 & 0.17 & 0.19 & 39 & 70 & -3.02 \\
\hline C-1252 & 53.3 & 49.4 & 0.21 & 0.20 & 26 & 70 & 7.23 \\
\hline Tunca 79 & 41.5 & 33.7 & 0.20 & 0.17 & 36 & 93 & 18.80 \\
\hline Çakmak 79 & 4.2 & 43.5 & 0.18 & 0.20 & 38 & 80 & 1.58 \\
\hline Kiziltan 91 & 61.8 & 45,4 & 0.22 & $0.1 \mathrm{~s}$ & 29 & 75 & 12.36 \\
\hline Akbaşak & 54.5 & 44.5 & 0.24 & 0.19 & 27 & 83 & 18.35 \\
\hline Kund. 1149 & 48.4 & 46.9 & 0.20 & 0.21 & 31 & 81 & 3.10 \\
\hline
\end{tabular}

\section{Sonuç}

Ulkemiz toprak ve iklim ozellikleri góz onunde tutulduğunda bitkilerin $\mathrm{B}$ beslenmeleri ile ilgili gizli soruniarının olabileceği gerçeği gơz ardı edilmemelidir. Kaldıki yapilan survey çalışmalan da bu durumu ortaya koymaktadır. Bu araştımmanın yapildığı Orta Anadolu tahıl ekimi yapiląn alanlarda toprakların yaklaşık \%62' sinde bitkiye yarayışı $B$ noksanlık sınırında $\left(0,5 \mathrm{mg} \mathrm{kg}^{-1}\right)$ olduğu belirlenmiştir. Buna ek olarak yapilan yoğun fosforlu gúbreleme ve uygulanan ' $P^{\prime}$ un bayôk çoğunluğunun yaklaşık \%90-95' lik bir bolumanon toprakta fiksasyona/transformasyona uğradığı (Hibbert ve ark. 1991: George, 1993) dusşünülürse ózellikie PXB interaksiyonu ónem kazanmaktadır. Bu çalışmada kullanilan 27 adet farklı buğday genotipinin $P$ uygulamalarına bağlı olarak B konsantrasyonlan ve B alimlari bírbirlerinden onemli ólçude farkliliklar göstermiştir. Bitkilerin B konsantrasyonu lle $P$ konsantrasyonu arasında, $P$ alımı ile $B$ konsantrasyonu arasında ve $B$ alımı ile $P$ alımı arasında onemll negatif korelasyonlar belirienmiștir (sırasıyla $r=0,671 ; \quad=0,381$ ve $r=-0,231$ ). Bu durum $P \times B$ interaksiyonunun buğdayda $B$ beslenmesi bakımindan ciddi sorunlar yaratabilecek ônemlilikte görölmektedir.

\section{Kaynaklar}

Anonim, 1997. Tarım Istatistikleri Ózeti. DiE, Yayin No: 2137. Ankara.

Berger, K. C., E. Truog, 1945. Boron availability in relation to soil reaction and organic matter content. Soil Sci. Soc. Am. Proc. 10: 113-116.

Bergmann, W. 1992. Nutritional Disorders of Plants. Gustav Fisher Verlag. Stuttgart.

Bingham, F. T., J. P. Martin, J. A. Chastain, 1958. Effects of phosphorus fertilization of California soils on minor element nutrition of eitrus, Soil Sci. 86: 24-31

Bingham, F. T, M. J. Garber, 1960. Solubility and avaliability of micronutrients in relation to phosphorus fertilization. Soil Sci. Soc, Amer. Proc. 24: 209-213.

Cooper, P. J. M., P. J. Gregory, D. Tully, H. C. Harris, 1987 Improving water use efficiency of annual ctops in the rainfed farming systems of west Asia and nort Alrica. Exp. Agriculture 23: 113-158,1987.

Dinkelaker, B., V. Römheld, H. Marschner, 1989. Citric acid excretion and precipitation of calcium citrate in the rhizosphere of white lupin (Lupinus albus L). Plant Cell Environ. 12: 285-292.

Elrashidi, M. A., G. A. O'Connor, 1982. Boron sorption and desorption in soils. Soil Sci. Soc, Am. J. 46: 27-31.

Eyüpoğlu, F. 1999. Torkiye Topraklarının Verimliilk Durumu, T.C. Başbakanlik Köy Hizmetleri Gen. Müd. Toprak ve Gübre Araş. Enst. Müd. Yay. (Baskıda).

Eyüpoğlu, F., I. Güçtemur, S, Talaz, S, 1999. Orta Anadolu Bölgesinde tahıl üretilen alanlann B kapsamlari. T.C Başbakanlik Köy Hizmetieri Gen. Mud. Toprak ve Gübre Araș. Enst. Müd. Yay. (Baskıda). 
Gabelman, W. H., G. C. Gerloff, 1983. The search for and interpretation of genetic controls that enhance plant growth under deficiency levels of a macro-nutrient. Plant Soil 72: $335-350$.

Gardner, W. K., D. A. Barber, D. G. Parbery, 1983. The acquisition of phosphorus by Lupinus albus L. III. The probable mechanism by which phosphorus movement in the soil-root interface is enhanced. Plant Soil 70: 107-124.

George, E. 1993. Growth and phosphate efficiency of grain legumes and barley under dryland conditions in nortwest Syria. Verlag Ulirich E. Grauer Wendlingen.

Graham, R. D. 1984. Breeding for nutritional characteristics in cereals. Adv. Plant Nutr. 1: 57-102. Güneș, A., M. Alpaslan, 2000. Boron uptake and toxicity in maize genotypes in relation to boron and phosphorus supply. J. Plant Nutr. 23 (4): 541-550.

Gupta, U. C. 1972. Interaction effects of boron and lime on barley. Proc. Soil Sci. Soc. Amer. 36: 332-334.

Gupta, U. C., J. A. Macleod, 1981. Plant and soil boron as influenced by soil pH and calcium sources on podzol soils. Soil Sci. 131 (1): 20-25.

Gupta, U. C., Y. W Jame, C. A. Campbell, A. J. Leyshon, W. Micholaichuk, 1985. Boron toxicitiy and deficiency. A Review Can. J. Soil Sci. 65: 381-409.

Hibberd, D. E., J. Standley, P. S. Want, D. G. Mayer, 1991. Responses to nitrogen, phosphorus and irrigation by grain sorghum on cracking clay soil in central Queensland. J. Exp. Agric. 31: 525-534.

Hoffland, E., R. J. A. van de Boogaard, 1992. Nelemans J.A., and Findenegg, G.R., Biosynthesis and root exudation of citric and malic acid in phosphate-starved rape plants. New Phytol. 122: 675-680.
Holevas C. D., D. A. Biris, 1980. Bitter pit-like symptoms in quinces: Effect of calcium and boron sprays on the control of the disorder. 319-326. In: D. Atkinson, J.E. Jackson, R.O. Sharples, W.M. Waller (Eds.). Mineral nutrition of fruit trees. Butterworths, Boston.

Kacar, B., H. Samet, 1996. Türkiye' de planlı dönemde kimyasal gübre üretimi ve tüketimi. Doğa Tr. J. Agr. Forestry. 20: 4147.

Kitson, R. E., M. G. Mellon, 1944, Colorimetric determination of phosphorus as molybdo-vanadophosphoric acid. Ind. Eng. Chem. Anal. Ed. 16: 379-383.

Marschner, H. 1995 Mineral Nutrition of Higher Plants. $2^{\text {nd }}$ Ed. Acedemic Press. New York.

Matar, A., J. Torrent, J. Ryan, 1992. Soil and fertilizer phosphorus and crop responses in the dryland Mediterranean zone. Adv. Soil Sci. 18: 81-146.

Moorby, H., P. H. Nye, R. E. White, 1985. The influence of phosphate nutrition on $\mathrm{H}$ ion efflux by young rape root. Plant Soil 84: 403-413.

Oyewole, O. I., E. A. Aduayi, 1992. Evaluation of the growth and quality of the "Ife Plum" tomato as affected by boron and calcium. J. Plant Nutr. 15(2): 199-209.

Pollard, A. S., A. J. Parr, B. C. Loughman, 1977. Boron in relation to membrane function in higher plants. J. Exp. Bot. 28: 831844.

Wolf, B. 1974. Improvements in the azomethine-H method for the determination of boron. Comm. Soil Sci. Plant Anal. 5(1): 39-44. 